\title{
APONTAMENTOS SOBRE O EDUCADOR AUDIOVISUAL: CINEMA, EDUCAÇÃO E ALTERIDADE
}

Alexandre Silva Guerreiro ${ }^{(*)}$

A relação entre cinema e educação ganha uma dimensão especial quando pensada a partir do conceito de alteridade. O educador audiovisual como sujeito intrínseco a essa relação constitui-se como um sujeito mobilizador de afetos pois é em torno dele que gira esta interface, voltada para a promoção dos processos de sensibilização e subjetivação de alunos e educadores. Pensar essa relação atravessada pela alteridade significa equacioná-la a partir do princípio de que o Outro é o componente central no ensino-aprendizagem.

Propomos, neste artigo, uma reflexão sobre os sujeitos da educação e, mais especificamente, sobre o educador audiovisual. Nesse cenário temos, de um lado, educadores que se encontram diante de novas tecnologias e novas formas de ensinar, e de outro, alunos colocados no lugar de protagonistas da educação, que aprendem na mesma medida em que ensinam. Iniciamos com uma reflexão sobre a escola, seu papel e as possibilidades de transformação para, num segundo momento, refletirmos sobre os atores sociais aqui envolvidos à luz dos conceitos de teórico amador, conforme definido por Jacques Rancière, que nos ajuda a colocar o educador numa relação de proximidade com o aluno, e de alteridade, formulado por Emanuel Lévinas (1988), que contribui para uma discussão sobre a centralidade do Outro no mundo contemporâneo. Refletimos, também, sobre a especificidade do trabalho do educador audiovisual e sua inserção no cenário escolar.

\section{CINEMA E EDUCAÇÃO NA SALA DE AULA}

As pesquisas na área de cinema e educação nos dão um número considerável de reflexões que pensam a inter-relação desses dois campos de variadas formas. Vale dizer que não é sem uma certa dose de idealização que, ocasionalmente, tanto a educação quanto o cinema são vistos. Ao discorrer sobre a escola, Fonseca (2010) nos dá o tom dessa idealização ao imaginar o espaço da sala de aula, que existe mais em nossos desejos e projeções do que na escola de fato.

[...] a sala de aula é, por excelência, um espaço plural, coletivo, o palco no qual professores e alunos/atores/sujeitos vivem, aprendem, ensinam, relacionam-se uns

\footnotetext{
(*) Doutor em Comunicação pelo PPGCOM/UFF. Atualmente, é Professor Docente I na Secretaria de Estado de Educação do Rio de Janeiro (SEEDUC/RJ) e desenvolve pesquisa de Pós-doutorado sobre "Escola, Cinema e Violência" no PPGE/UFRJ. Orcid: < https://orcid.org/0000-0003-0767-5054>. E-mail: alexandreguerreiro@ hotmail.com.
} 
com os outros, com o mundo, com os saberes. Ali eles se expressam, se expõem, se revelam, se colocam por inteiro, na totalidade. Objetividade e subjetividade, corpo e mente, razão e sensibilidade, o bio/psico/social em ação. Na sala de aula, o professor re/constrói sua bio/grafia, sua história, sua trajetória, sua experiência pessoal e profissional. Espaço de aprender e ensinar, logo, um espaço, um campo de relações. (FONSECA, 2010, p. 391)

Esse espaço sonhado e harmônico esbarra na constatação de que a escola nem sempre cumpre o papel que imaginamos ser o dela. Bourdieu (2015) aponta para o mito da escola libertária, sustentando que a escola é fruto de um sistema que não produziria, através dela, a semente de sua própria transformação. Antes, a escola seria mantenedora das desigualdades sociais. O que colocamos como central em nossos desejos é uma escola sonhada, que existe, ainda hoje, como exceção.

Ao atribuir aos indivíduos esperanças de vida escolar estritamente dimensionadas pela sua posição na hierarquia social, e operando uma seleção que - sob as aparências da equidade formal - sanciona e consagra as desigualdades reais, a escola contribui para perpetuar as desigualdades, ao mesmo tempo em que as legitima. (BOURDIEU, 2015, p. 65)

Poderíamos supor, porém, que reiterar nosso desejo de uma escola libertária, que busque transformar a realidade e o mundo, é desnecessário. No entanto, inúmeros elementos na educação atual nos apontam no sentido contrário, seja pela sobrevivência de modelos de avaliação pouco voltados para as subjetividades, seja pelas hierarquias que permanecem no interior de cada sala de aula e de cada escola.

Polêmicas à parte, podemos afirmar que, ao mergulharmos no universo da escola e da educação, é sempre importante pensarmos em qual escola queremos, na certeza de que existem muitas possibilidades de escola e de educação. Não é diferente quando abordamos o cinema na escola. Ferramenta pedagógica, mera ilustração do conteúdo, expressão artística capaz de sensibilizar e envolver seus atores sociais no processo de visionamento ou de realização de um filme, o cinema está na escola há muito tempo, mas quando pensamos em cinema e educação, não é, tampouco, qualquer cinema que queremos.

\section{O PAPEL DO EDUCADOR AUDIOVISUAL}

Para os que atuam na área do cinema e da educação, trabalhar nessa interface possibilita ativar os processos de subjetivação dos alunos, proporcionando sua emancipação intelectual e 
afetiva. Com efeito, se não existe uma única abordagem desses campos e se a diversidade e pluralidade é o que queremos, é na figura do educador que precisamos apostar, na sua sensibilização, no seu respeito pelo outro, na sua consciência de que os saberes docentes que importam não se adquirem apenas nas licenciaturas, mas durante toda a jornada profissional do educador, na relação com os alunos e com a diversidade.

O educador, vale salientar, não se confunde com a instituição-escola. Não raramente, para implementar seu trabalho da maneira como ele acredita, o educador precisa lutar contra um sistema que massifica e violenta o corpo discente, seja através de avaliações desumanas e excludentes, seja nas relações hierarquizantes e superficiais que podem existir no interior de uma escola. A sala de aula idealizada de que nos fala Fonseca é e será tudo aquilo se, e somente se, o educador souber construir um espaço em que uma relação mútua de igualdade na diferença, sensibilidade e afeto se estabeleça de forma plena.

Sendo assim, por mais que acreditemos na escola, é da relação entre educador e aluno que surge uma real possibilidade de transformação da educação, da sociedade e do mundo. Essa relação transcende a sala de aula e se impõe de maneira radical como um elemento verdadeiramente revolucionário, pois a partir do canal de comunicação que os educadores estabelecem com seus alunos, vidas são transformadas, realidades são questionadas e novos horizontes, construídos.

Como, então, pensar no papel do educador audiovisual dentro do cenário da educação nos dias atuais? Qual a especificidade de seu ofício? Em primeiro lugar, o educador audiovisual é um educador e, como tal, ele deve ser considerado em toda a sua complexidade, não apenas um profissional que irá adquirir os saberes docentes necessários para sua atuação em sala de aula, mas como alguém que se manterá no aprendizado constante que advém da sua relação com os alunos, numa formação continuada ao longo de sua carreira. Antes de tudo, é preciso combater os processos de racionalização da formação docente tão presentes para resgatar a importância da figura do educador com profundidade. Lelis (2014) nos lembra sobre uma indesejável tendência mundial na formação dos educadores:

[...] formas de regulação da profissão docente são necessárias. Mas elas devem respeitar a experiência do mestre e levar em consideração os processos dinâmicos e interativos de formação contínua, vividos em espaços concretos pelo coletivo que constitui esse grupo profissional. Todavia, o que se vê hoje, em vários países do mundo, obedece a uma lógica que privilegia a racionalização técnica do trabalho professoral em vários níveis. (LELIS, 2014, p.54). 
Valorizar os saberes docentes como dinâmicos e a formação continuada do educador é, sobretudo, assumir que algo lhe escapa, que seu ofício só se completa quando existe a interação professor-aluno a cada aula, e que essa relação precisa ser construída sobre os parâmetros da alteridade e da liberdade, respeitando cada um dos alunos, com suas visões de mundo e questões individuais, envolvidos na experiência de sala de aula. Nesse sentido, o movimento de nivelar os alunos, torná-los iguais, é um movimento de violência contra uma interação que se quer dinâmica e baseada na reciprocidade. Só a partir de uma construção coletiva dos saberes, o educador promoverá uma experiência genuína de aprendizado para ele e para todos os alunos envolvidos no processo.

Outro ponto a considerar é que o cinema está na escola de múltiplas formas. As licenciaturas devem fazer um esforço para sensibilizar professores das diversas disciplinas para trabalhar com o cinema. Sem dúvida que nosso desejo é que o cinema entre na escola como alteridade (BERGALA, 2002), mas é preciso entender a escola, também, em sua complexidade. O fato é que, mesmo quando esse desejo se realiza, o cinema não deixa de estar na escola de outras formas, nas diversas disciplinas e como ferramenta nas mãos dos outros profissionais da educação. Não acreditamos em nenhum caráter restritivo do uso do cinema na escola e não queremos afirmar que ele só pode existir da maneira que defendemos. O que podemos querer é que surja em todos os docentes um educador audiovisual em potencial, que se coloque diante do cinema como obra de arte, que se deixe transformar pelo cinema na mesma medida em que promova uma transformação dos seus alunos, dentro de suas disciplinas específicas. Ser um educador audiovisual é, sobretudo, ter uma sensibilidade diante do som e da imagem de cada obra, reconhecer seu poder emancipador, problematizando o mundo e a vida de uma forma geral, dentro ou fora da sala de aula, dentro ou fora de uma disciplina específica dedicada ao audiovisual. Queremos a arte presente na escola de todas as formas. Acreditar na possibilidade de sensibilização do educador para o audiovisual é garantir e amplificar o alcance do cinema que se quer na escola.

A demanda por educadores audiovisuais formados para desenvolver trabalhos especificamente com o cinema tende a aumentar, no entanto, isso não exclui a inserção do audiovisual nas licenciaturas de forma intensa, nas mais diversas áreas, como estratégia para que todo professor se torne um educador audiovisual em potencial. Esse é um caminho de luta, de criação de políticas públicas de cinema e educação, de relativização dos saberes cristalizados na educação atrelados a determinadas disciplinas para que o próprio ensino se transforme de maneira mais profunda. Essa formação profissional nos faz pensar, então, em outro ponto importante: que saberes sobre o próprio cinema o educador audiovisual e os educadores em geral precisam ter? De 
certo, o saber técnico é tão importante quanto qualquer outro saber relacionado ao cinema, e a reflexão teórica e o conhecimento de estéticas e da linguagem audiovisual devem ser colocados em primeiro plano.

\section{O EDUCADOR AUDIOVISUAL COMO UM TEÓRICO AMADOR}

A discussão que precisa ser feita, e que passa tanto pelo ementário das disciplinas das licenciaturas quanto pela transformação dos currículos escolares, nos faz olhar também para a relação com o outro, com os alunos, com seus saberes individuais. O cinema e seu entorno nos atravessa mesmo antes de pisarmos na escola. A onipresença da televisão em nosso país, a internet e os dispositivos móveis trazem o audiovisual para o dia a dia de uma maneira avassaladora. Isso, no entanto, não garante uma sensibilização diante do cinema ou da arte em geral e, por consequência, uma sensibilização diante do mundo. Ao entrar em contato com os vários universos que habitam uma sala de aula, por trás dos saberes de cada aluno, o educador audiovisual deve somar seus saberes, interagir, valorizar o saber do outro e aprender com ele. Não se trata de impor o cinema de sua preferência ou os seus saberes. Não se pode impor aquilo que uma certa casta social considera como sendo o bom cinema.

Talvez o movimento mais importante do educador audiovisual seja perder-se do seu cinema para ir ao encontro dos saberes dos alunos. Considerar que existe, nesse ínterim, um conteúdo a ser ensinado pode ferir de morte uma relação que tem um incrível potencial de fazer acontecer algo especial no encontro do cinema com a sala de aula. Nossa primeira crença deveria ser: o cinema já está lá na soma dos mundos dos alunos, o cinema já existe neles. O que queremos é fazer aflorar uma sensibilidade diante do cinema e do mundo, e para isso, não se pode impor um cinema como sendo bom, desqualificando o deles como sendo menor. Se queremos propiciar um encontro de inteligências de fato, seguindo a formulação de Rancière (2007), não há outro caminho a não ser valorizar o cinema que já existe em cada um de nós.

Deixar que o cinema nos escape. Por mais contraditório que isso possa parecer para quem trabalha com cinema e educação, pensamos ser esse um movimento importante para que a interface cinema e educação não gere um novo profissional detentor de um saber específico, e que se transforme, como em outras áreas, em autoridade. Pelo contrário, é preciso contaminar as outras áreas, metamorfosear os professores e seus saberes específicos em educadores sensíveis e prontos para trabalhar com o cinema e com a arte. 
O educador audiovisual precisa ir ao encontro dos mundos que habitam a escola tradicional, levar o germe da mudança, transformar o sistema de dentro para fora. Para isso, ele precisa abrir mão dessa autoridade em relação aos saberes que constituíram sua formação. Recusar o bom cinema é abrir-se para o cinema do outro, o mundo do outro; é entender que o bom cinema só existe dentro de uma relação que denota poder, elitismo, hierarquização. O cinema que habita em cada aluno é sua visão de mundo, formada também, e sobretudo, pela onipresença do audiovisual na contemporaneidade. Negar seu cinema é negar sua visão de mundo, é impor o nosso mundo sobre o dele. Achar que só é possível sensibilizar o olhar através do cinema que trazemos em nós é perder o melhor do encontro, é desequilibrar a relação.

Sejamos, então, como o teórico amador de que nos fala Rancière. Segundo o autor,

O amadorismo é também uma posição teórica e política, a que recusa a autoridade dos especialistas, sempre a reexaminar o modo como as fronteiras entre suas áreas se traçam na encruzilhada das experiências e os saberes. A política do amador afirma que o cinema pertence a todos aqueles que, de uma ou de outra maneira, viajaram dentro do sistema de desvios que esse nome instaura, e que cada um se pode permitir traçar, entre este ou aquele ponto dessa topografia, um itinerário próprio, peculiar, o qual acrescenta ao cinema como mundo e ao seu conhecimento. (RANCIÈRE, 2012, p.16).

Nesse sentido, não há conteúdo a ser passado na medida em que cada aluno atua na produção de sentido diante de um filme; não há evolução entre as experiências de visionamento ou realização dos filmes na escola. O educador audiovisual abre-se, assim, à escuta, à interação, ao protagonismo dos alunos diante do audiovisual. Levar o cinema para a sala de aula com um planejamento fechado é perder algo. É preciso se manter aberto ao que o cinema pode provocar quando alunos e educadores se posicionam em torno dele, rompendo a lógica da espacialidade e da racionalidade que imperam ainda hoje.

Não resta dúvida de que essa postura do educador audiovisual vai na contramão do que se estabelece como sendo o papel social do professor, detentor de um saber a ser ensinado, apreendido pelos alunos, e que será posteriormente cobrado através de um sistema de avaliações e julgamentos. Manter uma certa dose de amadorismo significa abrir mão do lugar de especialista, de autoridade, dividindo o lugar do conhecimento com os alunos numa relação de igualdade plena, preservando as diferenças. Isso não quer dizer que o educador não tenha seus saberes docentes, mas reafirma que os saberes discentes são igualmente importantes, e que, dentre todos os saberes docentes, nada é mais fundamental do que desenvolver a competência de sensibilizar os alunos e sensibilizar-se com eles. Sem um educador audiovisual capaz de promover processos de subjetivação e uma relação de 
igualdade na diferença, não há sensibilização possível. Eis o principal ponto na formação de um educador audiovisual.

\section{CINEMA, EDUCAÇÃO E ALTERIDADE}

As possibilidades abertas pelo cinema são imensas. Entendemos cinema, aqui, em sentido amplo, como matriz de um universo audiovisual que nos envolve a todos. Tirar o cinema do lugar que ele já ocupa na escola requer engajamento e esclarecimento, vontade política e desejo. Requer, também, a formação de profissionais cientes da importância de colocar as relações de afeto e de subjetivação em primeiríssimo plano. O educador audiovisual não deve estar na escola com a intenção de formar cineastas ou de destilar seu conhecimento técnico. O desenvolvimento tecnológico dos últimos anos dotou a escola contemporânea da incrível capacidade de realizar filmes com e pelos alunos. No entanto, essa vantagem não pode se converter numa preocupação com a técnica. Aqui, também, o cinema precisa ser esquecido e redescoberto. Fazer cinema na escola não é um simples fazer cinema, talvez seja o mais importante fazer cinema de todos justamente porque não se trata de formar cineastas ou especialistas, mas de emancipar cidadãos, de afetar sujeitos.

Nesse sentido, o cinema não importa, o que importa é o sujeito. O mesmo podemos dizer sobre a educação. Isso significa afirmar que a arte, o cinema, a educação e o conhecimento não são em si, eles são o que fazemos deles. Aliás, educa-se, também, para a violência, para o preconceito, para a discriminação ${ }^{1}$. O cinema e a educação que queremos são aqueles que garantem os processos de subjetivação dos alunos e professores, e nesse sentido, ambos são menores do que os sujeitos. Buscar essa radicalidade na nossa relação com o cinema na escola nos leva, então, a perdê-lo para, num segundo momento, recuperá-lo transformado em afeto. O cinema que nos escapa encontra o outro fora da lógica da centralidade do Eu, do ensino unilateral, da objetificação. Sujeitos ao afeto, alunos e professores encontram-se com o cinema, numa reconstrução que nos devolve o cinema transformado. O educador audiovisual, por esse viés, é alguém preparado para o imprevisto, aberto ao que nenhum plano de aula poderá antecipar, livre. Ele não se confunde com a escola, ele é, em si, uma instituição revolucionária capaz de reinventar espaços e relações junto aos que compartilham com ele o espaço escolar, que por ele são afetados e que o afetam de volta, na mesma

\footnotetext{
${ }^{1}$ Aqui, vale lembrar como artistas e professores se envolveram com o ideário nazista. Leni Riefenstahl dirigiu filmes de forte apelo estético para o nazismo e o filósofo Martin Heidegger, a despeito de seus escritos sobre o humanismo, filiou-se ao Partido Nazista e assumiu a reitoria da Universidade de Friburgo, na Alemanha de Adolf Hitler.
} 
medida. É a centralidade do Outro que precisa atravessar as relações no mundo, dentro e fora da escola.

Emmanuel Lévinas é considerado o filósofo da alteridade. O desafio que enfrentamos hoje é o de fazer valer o pensamento de Lévinas de maneira plena. Como superar o legado de uma tradição filosófica bimilenar que coloca o Eu no lugar central e tomar as proposições levinasianas em sua plenitude?

O absolutamente Outro é Outrem: não faz número comigo. A colectividade [sic] em que eu digo "tu” ou "nós" não é um plural de "eu”. Eu, tu, não são indivíduos de um conceito comum. Nem a posse, nem a unidade do número, nem a unidade do conceito me ligam a outrem. Ausência de pátria comum que faz do Outro - o Estrangeiro; o Estrangeiro qyue [sic] perturba o "em sua casa". Mas o Estrangeiro quer dizer também o livre. Sobre ele não posso poder, porquanto escapa ao meu domínio num aspecto essencial, mesmo que eu disponha dele; é que ele não está inteiramente no meu lugar. (LÉVINAS, 1988, p.26, grifos no original)

Ao colocar o Outro no lugar central, Lévinas desafia a formação do nosso pensamento, invertendo as convicções e comportamentos do eu-sujeito. Não seria essa lógica, a do Eu no lugar central, que de alguma forma fundamenta, através dos séculos, boa parte das agruras que atravessaram a humanidade? O que subjaz aos interesses geopolíticos e econômicos de uma guerra se não a ideia de dominação do Outro? Do ciúme mais corriqueiro aos crimes passionais, muitos deles legitimados pela sociedade durante tanto tempo sob a argumentação de defesa da honra, não estamos sempre atravessados pela ideia de dominação sobre Outrem, o Outro sempre como complementação do Eu ou como meu inimigo? E o que falar das religiões em seus processos de angariar seguidores, de transformar o Outro em Eu através de um ideário religioso e da existência de um Deus que nos converta, literalmente, no mesmo? A saída está, necessariamente, na centralidade do Outro.

Desejo do outro como necessidade daquele que não tem mais necessidades, que se reconhece na necessidade de um Outro que é Outrem, que não é nem meu inimigo [...], nem meu "complemento" [...], que é constituída porque faltaria alguma coisa à subsistência de cada indivíduo. (LÉVINAS, 1993, p.48-49)

A escola que queremos deve ser construída a partir da noção de alteridade. A importância da educação é inquestionável e o desejo de que a mesma tenha qualidade é consenso geral. Porém, ainda se vê essa qualidade atrelada ao acúmulo de conhecimento, à preparação para o mercado de trabalho ou para avaliações exteriores à escola e que alçarão o aluno a outros patamares na pirâmide escolar, da educação básica à universidade. Os processos de subjetivação, o protagonismo de 
professores e alunos, o cinema como elemento de desequilíbrio das formas como a escola tradicionalmente se organiza, a educação voltada para uma verdadeira emancipação dos atores envolvidos: é a partir da reinvenção da escola que alguma mudança é possível, e essa reinvenção só pode ocorrer por vontade política de fora, que depende de inúmeros fatores externos e muitas vezes alheios aos nossos desejos, e de dentro, a cada vez que o professor fecha a porta da sala de aula e deixa o novo acontecer.

\section{CONSIDERAÇÕES FINAIS}

A relação entre cinema e educação, plural, inventiva, necessária, precisa estar na escola cada vez com mais vigor, mas precisa acreditar no educador, de uma maneira geral, e no educador audiovisual, especificamente. Os alunos e seus mundos estão lá, e não importa se estão lá por imposição ou porque a sociedade e a família não lhes deram outra alternativa. No menor movimento que o educador fizer, esses mundos entrarão em contato de maneira plena e intensa.

Os alunos são e sempre foram a força da educação. Seu protagonismo é natural e o apagamento das diferenças ou o nivelamento de seus corpos e mentes é artificial, fruto de sistemas repressores que querem, simplesmente, controlar seus futuros cidadãos. A escola mantenedora de certo status quo coexiste com a escola transformadora que almejamos. O papel do educador audiovisual, ao proporcionar uma experiência de verdadeira liberdade, deixando esse protagonismo natural acontecer, é um papel revolucionário.

Nesse sentido, é preciso colocar o aluno acima de tudo, do próprio cinema, do próprio sistema, da própria educação. Cinema, educação e alteridade, nesse sentido, formam uma tríade capaz de conduzir nossas ações e de reinventar a escola a partir do trabalho do educador audiovisual. Essa é uma forma de encontrar um novo sentido na escola, de reencontrar o cinema como forma de afetação do sujeito, de pensar a educação como maneira de emancipar os alunos e, acima de tudo, é um sinal de que a transformação do mundo a partir da sala de aula é possível. 


\section{REFERÊNCIAS}

BERGALA, A. A hipótese-cinema: pequeno tratado de transmissão do cinema dentro e fora da escola. Rio de Janeiro: Cinead/UFRJ/Booklink, 2002.

BOURDIEU, P. A escola conservadora: as desigualdades frente à escola e à cultura. In: Escritos de Educação. Petrópolis, RJ: Vozes, 2015.

FONSECA, S. O Trabalho do professor na sala de aula: relações entre sujeitos, saberes e práticas. Revista Brasileira de Estudos Pedagógicos, Brasília, v. 91, n. 228, p. 390-407, maio/ago. 2010.

LELIS, I. A construção social da profissão docente no Brasil: uma rede de histórias. In: TARDIF, M; LESSARD, C. O ofício do professor: história, perspectivas e desafios internacionais. Petrópolis, RJ: Vozes, 2014.

LÉVINAS, E. Humanismo do outro homem. Petrópolis: Vozes, 1993.

Totalidade e infinito. Lisboa: Edições 70, 1988.

RANCIÈRE, J. As distâncias do cinema. Rio de Janeiro: Contraponto, 2012.

. O Mestre Ignorante: cinco lições sobre a emancipação intelectual. Belo Horizonte: Autêntica, 2007. 


\section{RESUMO}

O presente artigo busca refletir sobre o educador audiovisual como sujeito intrínseco à relação que se estabelece entre cinema e educação, na medida em que a essa relação atrelamos o conceito de alteridade. Para isso, implementamos uma investigação sobre a escola e o papel do educador para, em seguida, explorarmos os conceitos de teórico amador, criado por Jacques Rancière (2012) como um delineador do educador na contemporaneidade, e de alteridade, conforme formulada por Emanuel Lévinas (1988), entendendo o Outro como central. Essas duas abordagens nos conduzem à formulação de que os atores sociais envolvidos nessa relação são sujeitos de afeto, atravessados pelas questões que envolvem cinema, educação e alteridade na contemporaneidade.

Palavras-chave: Audiovisual; Educação; Alteridade.

\section{APPOINTMENTS ABOUT THE AUDIOVISUAL EDUCATOR: CINEMA, EDUCACION AND OTHERNESS}

\section{ABSTRACT}

The present paper aims to analyse about the audiovisual educator as an intrinsic subject to the relationship established between cinema and education, insofar as to this relationship we link the concept of otherness. Aiming for it, we implemented an investigation about the school and the role of the educator in order to explore the concepts of amateur theorist, created by Jacques Rancière (2012) as an educator's definition in contemporary times, and of otherness, as formulated by Emanuel Lévinas (1988), understanding the Other as central. These two approaches lead us to the formulation that the social actors involved in this relationship are subjects of affection, crossed by the issues that involve cinema, education and otherness in the contemporary world.

Keywords: Audiovisual; Education; Otherness.

\section{APUNTES SOBRE EL EDUCADOR AUDIOVISUAL: CINEMA, EDUCACIÓN Y OTREDAD}

\section{RESUMEN}

El presente artículo busca reflexionar sobre el educador audiovisual como sujeto intrínseco a la relación que se establece entre cine y educación, en la medida en que a esa relación atamos el concepto de otredad. Para eso, implementamos una investigación sobre la escuela y el papel del educador para luego explorar los conceptos de teórico aficionado, creado por Jacques Rancière (2012) como un delineador del educador en la contemporaneidad, y de alteridad, conforme formulada por Emanuel Lévinas (1988), entendiendo el Otro como central. Estos dos enfoques nos conducen a la formulación de que los actores sociales involucrados en esa relación son sujetos de afecto, atravesados por las cuestiones que involucran cine, educación y otredad en la contemporaneidad.

Palabras clave: audiovisual; la educación; Otredad.

Submetido em 30 de julho de 2019

Aprovado em 01 de setembro de 2019 